\title{
Theoretical Predictions of Properties and Chemical Behavior of Superheavy Elements
}

\author{
V. Pershina* \\ Gesellschaft für Schwerionenforschung, D-64291 Darmstadt, Germany
}

Received: November 13, 2001; In Final Form: March 25, 2002

Fully relativistic electronic structure calculations have been performed for gas phase and aqueous phase compounds of elements 104 through 108. Based on these calculations, volatility and complex formation, as well as trends in these properties, have been predicted. The transactinide compounds were shown to exhibit properties very similar to those of the lighter homologs in the respective chemical groups. Some deviations from the observed trends were established.

\section{Introduction}

Fast progress in experimental investigations of chemical properties of the heaviest elements gives further impact to theoretical studies. Most of them are aimed at prediction of chemical behavior in sophisticated and expensive experiments with single atoms.

Recently, elements $107(\mathrm{Bh})^{1}$ and $108(\mathrm{Hs})^{2}$ were chemically identified using gas-phase chromatography techniques. They were shown to form $\mathrm{BhO}_{3} \mathrm{Cl}$ and $\mathrm{HsO}_{4}$ in analogy with lighter elements in the chemical groups $\mathrm{Re}$ and $\mathrm{Os}$, respectively. Besides, the behavior of $\mathrm{Rf}$ and $\mathrm{Sg}$ which had already been characterized chemically has meanwhile been further studied in more detail. In some cases, deviations from trends in properties found for lighter homologs in the groups were observed or conflicting results of experiments conducted at the same conditions were reported. Thus, for example, results of various experiments on the extraction of $\mathrm{Zr}$, Hf, and $\mathrm{Rf}$ from $\mathrm{HF}$ and $\mathrm{HCl}$ solutions ${ }^{3-6}$ disagreed concerning extraction sequences (see the review of $\mathrm{Kratz}^{5}$ ): Cation exchange separations (CIX) of $\mathrm{Zr}$, Hf, and Rf from HF solutions, have given the following trend in ascending $K_{d}$ values: $\mathrm{Zr}>\mathrm{Hf}>\mathrm{Rf}$, while in the anion exchange (AIX) separations, $\mathrm{Rf}$ and $\mathrm{Hf}$ though behaving similar, were much less $\mathrm{ab}$ sorbed on the AIX than $\mathrm{Zr}^{3}$ In contrast to results of Reference 3, recent $\mathrm{AIX}$ separations ${ }^{4}$ of group 4 elements from aqueous $\mathrm{HCl}$ solutions performed at the same conditions have shown an inversed sequence in rising $K_{d}$ values: $\mathrm{Rf}>\mathrm{Zr}>\mathrm{Hf}$. The TBP extraction of group 4 elements from $8 \mathrm{M} \mathrm{HCl}$, however, showed the position of $\mathrm{Rf}$ in between those of $\mathrm{Zr}$ and $\mathrm{Hf}: \mathrm{Zr}>\mathrm{Rf}>\mathrm{Hf}^{6}{ }^{6}$ Thus, extraction behavior of group 4 elements from $\mathrm{HF}$ and $\mathrm{HCl}$ solutions have not yet been established with a high certainty.

Another open question was the hydrolysis of Rf. In Reference 7, a conclusion about stronger hydrolysis of $\mathrm{Rf}$ in comparison with that of $\mathrm{Zr}$ has been drawn by studying sorption of group 4 elements and Th on cobalt ferrocyanite surfaces, while results of the AIX separations come to a different conclusion. ${ }^{8}$

Group 5 elements were also shown to exhibit an unexpected, inversed, trend in the complex formation and extraction from aqueous acidic $\mathrm{HCl}$ solutions $\mathrm{Nb}>\mathrm{Db}>\mathrm{Ta}{ }^{9}$

Solution chemistry on element 106 has shown first interesting results: In experiments on the elution of group- 6 elements from cation exchange columns in $0.1 \mathrm{M} \mathrm{HNO}_{3}, \mathrm{Sg}$ was not eluted from the column in contrast to $\mathrm{W} .{ }^{10}$ This non-tungsten-like behavior of Sg was tentatively attributed to its lower tendency to hydrolyze as compared to that of tungsten. All those open questions needed answers or theoretical interpretation.

In our previous research, numerous gas phase and aqueous phase compounds were studied theoretically. Trends in various physico-chemical properties in the transition element groups and along the last transition-element row have been defined, as well as influence of relativistic effects of those properties has been elucidated. The reviews of those works are given in References 11,12 . To assist new experimental efforts and to solve the accumulated problems, our theoretical research has been extended to the consideration of the above mentioned processes and compounds.

In the current publication, we overview results of the recent investigations of the electronic structure and properties of gaseous species of $\mathrm{Bh}$ and $\mathrm{Hs}$, as well as of hydrolysis and complex formation of $\mathrm{Rf}, \mathrm{Db}$, and $\mathrm{Sg}$ in aqueous acidic solutions along with their homologs in chemical groups.

\section{Method and Details of the Calculations}

Calculations of the electronic structure of the above mentioned compounds were performed using the fully relativistic Density-Functional Theory (DFT) method with the General Gradient Approximation (GGA) for the exchange-correlation energy. ${ }^{13,14}$ The method is a fully relativistic all-electron (or frozen core, FC, if necessary) code with the spin-orbit coupling explicitly included. It uses four-component basis functions which are transformed into molecular symmetry orbitals using double point groups. Molecular integrals between these functions are calculated in a numerical, three-dimensional grid. The most recent version of the method includes minimization of an error in the total energy ${ }^{15}$ and the integration scheme of Boerrigter et al., ${ }^{16}$ which altogether give much more accurate results for total energies.

The Dirac Hamiltonian is

$$
h_{D}=c \alpha \pi+(\beta-1) c^{2}+V,
$$

where the potential is the sum of three parts

$$
V=V_{n}+V_{c}+V_{x}
$$

with $V_{n}$ the nuclear, $V_{c}$ the Coulomb, and $V_{x}$ is a functional derivative of the exchange-correlation energy. The GGA of Becke $^{17}$ and Perdew ${ }^{18}$ is included perturbatively in order to consider non-local contributions. In the GGA calculations, the relativistic form of the exchange-correlation potential developed by Engel et al. ${ }^{19}$ was used.

The present calculations have been performed within the FC approximation for the group 4, 5, and 6 aqueous phase complexes and for all-electrons for group 7 and 8 gas-phase compounds. The number of integration points was $10^{4}$. The Mulliken population analysis ${ }^{20}$ was applied for the electronic density distribution. The results were then further used for some physico-chemical models in order to link measured and calculated properties.

\section{Results and their Discussion}

3.1. Gas-phase Complexes

3.1.1. Group 7 Oxyhalides. Results of the RGGA DFT cal-

*E-mail: V.Pershina@gsi.de. 
TABLE 1: Effective charges $\left(Q_{M}\right)$, overlap populations (OP), ionization potentials (IP), dipole moments $(\mu)$, electric dipole polarizabilities $(\alpha)$, dissociation (atomization) energies $\left(\Delta H_{\text {diss }}\right)$ for $\mathrm{MO}_{3} \mathrm{Cl}$, where $\mathrm{M}=\mathrm{Tc}, \operatorname{Re}$, and $\mathbb{B h} .{ }^{21}$

\begin{tabular}{cccc}
\hline Property & $\mathrm{TcO}_{3} \mathrm{Cl}$ & $\mathrm{ReO}_{3} \mathrm{Cl}$ & $\mathrm{BhO}_{3} \mathrm{Cl}$ \\
\hline$Q_{\mathrm{M}}$ & 1.28 & 1.21 & 1.13 \\
$\mathrm{OP}$ & 1.93 & 2.20 & 2.31 \\
$\mathrm{IP} / \mathrm{eV}$ & 12.25 & 12.71 & 13.05 \\
$\mu / D$ & 0.93 & 1.29 & 1.95 \\
$\alpha / 10^{-24} \mathrm{~cm}^{3}$ & 4.94 & 5.91 & 7.50 \\
$\Delta H_{\text {diss }} / \mathrm{eV}$ & 23.12 & $24.30^{a}$ & 22.30 \\
\hline
\end{tabular}

${ }^{a}$ Thermochemical $\Delta H_{\text {diss }}$ calculated via a Born-Haber cycle is $23.76 \mathrm{eV}$.

culations $^{21}$ of the electronic structure of group 7 oxychlorides $\mathrm{MO}_{3} \mathrm{Cl}(\mathrm{M}=\mathrm{Tc}, \mathrm{Re}$, and $\mathrm{Bh})$ are summarized in Table 1. Typically of the transition elements in groups $4-6$, the electronic structure of the $\mathrm{Bh}$ compound is very similar to those of $\mathrm{Tc}$ and Re. The values of the effective charge $\left(Q_{\mathrm{M}}\right)$ and overlap population (OP, which is a measure of covalence) show $\mathrm{BhO}_{3} \mathrm{Cl}$ to be the most covalent compound in the row. Dipole moments and electric dipole polarizabilities of $\mathrm{MO}_{3} \mathrm{Cl}$ increase in the group from $\mathrm{Tc}$ to $\mathrm{Bh}$.

To predict adsorption energy, $\Delta H_{\mathrm{ads}}$, of $\mathrm{BhO}_{3} \mathrm{Cl}$ on the quartz surface of the gas chromatography column, needed for the gasphase chromatography experiments, the following model of physisorption was used. The quartz surface was supposed to be covered with adsorbed $\mathrm{Cl}$. The molecule-surface interaction energy in this case was considered of consisting of three parts: molecular dipole - effective charge on $\mathrm{Cl}$, molecular polarizability - effective charge on $\mathrm{Cl}$ and molecular polarizability polarizability of $\mathrm{Cl}$, so that

$$
\begin{gathered}
\varepsilon(\text { molecule- surface } \mathrm{Cl})=\varepsilon(\mu, Q e)+\varepsilon(\alpha, Q e)+\varepsilon(\alpha, \alpha) \\
=-\frac{2 \mu Q e}{x^{2}}-\frac{Q^{2} e^{2} \alpha}{2 x^{4}}-\frac{3}{2} \frac{\alpha_{1} \alpha_{2}}{x^{6}\left(\frac{1}{h v_{1}}+\frac{1}{h v_{2}}\right)} .
\end{gathered}
$$

Here, $h v_{1}$ and $h v_{2}$ denote approximately IP of the molecule and of $\mathrm{Cl}^{Q-}$, with the latter being a function of $Q$ (see Reference 21 ). The only unknown value in eq 3 was that of $x$. It could be deduced, e.g. for $\mathrm{ReO}_{3} \mathrm{Cl}$, by setting eq 3 equal to the experimentally measured $\Delta H_{\text {ads }}=-61 \mathrm{~kJ} / \mathrm{mol}$ for a typical value of $Q(\mathrm{Cl})=-0.4$. This has given $x=3.38 \AA$. Taking this value as a benchmark and assuming that the molecule-surface distance was directly related to the size of the interacting molecules, $\Delta H_{\text {ads }}=-48.2 \mathrm{~kJ} / \mathrm{mol}$ for $\mathrm{TcO}_{3} \mathrm{Cl}$ and $\Delta H_{\mathrm{ads}}=-77.6 \mathrm{~kJ} / \mathrm{mol}$ for $\mathrm{BhO}_{3} \mathrm{Cl}$ were determined. ${ }^{21}$ The increasing adsorption enthalpies (due to increasing dipole moments) mean that volatility changes in the following order: $\mathrm{TcO}_{3} \mathrm{Cl}>\mathrm{ReO}_{3} \mathrm{Cl}>\mathrm{BhO}_{3} \mathrm{Cl}$. The experimentally determined $\Delta H_{\text {ads }}=-77.8 \mathrm{~kJ} / \mathrm{mol}$ (Ref. 1) agreed very well with these predictions.

3.1.2. Group 8 Tetroxides. In a similar way, volatility of $\mathrm{MO}_{4}(\mathrm{M}=\mathrm{Ru}, \mathrm{Os}$, and $\mathrm{Hs})$ was predicted in Reference 22. For that purpose, the RGGA DFT fully relativistic calculations have been performed for those molecules. Results of the calculations are summarized in Table 2 . As in the case of group 7 oxychlorides, $\mathrm{HsO}_{4}$ was found to exhibit properties very similar to those of $\mathrm{OsO}_{4}$, and it is the most covalent and stable compound in the group, as the binding energies $\left(\Delta H_{\text {diss }}\right)$ show. The $Q_{\mathrm{M}}$ and $\mathrm{OP}$ data are indicative of an increase in covalence from $\mathrm{RuO}_{4}$ to $\mathrm{HsO}_{4}$. Such an increase is typical of various other compounds of the transactinides and is accounted for by strong relativistic stabilization of the $7 s$ and $7 p_{1 / 2}$ valence orbitals. The calculated IPs show very good agreement with the experiment for $\mathrm{RuO}_{4}$ and $\mathrm{OsO}_{4}$ (Table 2). The calculated polarizabilities show a "zigzag" behavior in the group, with the lowest value for $\mathrm{OsO}_{4}$.

Predictions of adsorption enthalpies of $\mathrm{MO}_{4}(\mathrm{M}=\mathrm{Ru}, \mathrm{Os}$, and Hs) were made in a similar manner as those for the group 7 oxychlorides. For that purpose, a molecule-slab interaction model
TABLE 2: Effective charges $\left(Q_{M}\right)$, overlap populations (OP), ionization potentials (IIP), and dissociation energies $\left(\Delta H_{\text {diss }}\right)$ for $\mathrm{MO}_{4}$, where $\mathrm{M}=\mathrm{Ru}, \mathrm{Os}$, and $\mathrm{Hs}^{22}$

\begin{tabular}{cccc}
\hline Property & $\mathrm{RuO}_{4}$ & $\mathrm{OsO}_{4}$ & $\mathrm{HsO}_{4}$ \\
\hline$Q_{\mathrm{M}}$ & 1.45 & 1.46 & 1.39 \\
$\mathrm{OP}$ & 1.92 & 1.94 & 2.17 \\
$\mathrm{IP} / \mathrm{eV}$ (calc) & 12.25 & 12.35 & 12.28 \\
$\mathrm{IP} / \mathrm{eV}(\mathrm{exp})^{a}$ & 12.19 & 12.35 & \\
$\alpha / 10^{-24} \mathrm{~cm}^{3}$ & 6.48 & 5.96 & 6.26 \\
$\Delta H_{\text {diss }} / \mathrm{eV}$ & 27.48 & 27.71 & 28.44 \\
\hline
\end{tabular}

${ }^{a}$ Reference 23 .

was used where the interaction energy was integrated over the volume of a solid. The molecule - quartz surface interaction energy was considered to be of a pure van der Waals type described by the following expression ${ }^{22}$

$$
E(x)=-\frac{3}{16}\left(\frac{\varepsilon-1}{\varepsilon+2}\right) \frac{\alpha_{\text {mol }}}{\left(\frac{1}{h v_{\text {slab }}}+\frac{1}{h v_{\text {mol }}}\right) x^{3}}
$$

where $\varepsilon=3.81$ is the dielectric constant of quartz. The interaction distance $x$ was defined for $\mathrm{OsO}_{4}$ in a similar way as it was done for $\mathrm{ReO}_{3} \mathrm{Cl}$. Using experimental values of $\alpha$ and IP (Table 2) for $\mathrm{OsO}_{4}$ and setting eq 4 equal to $-38 \mathrm{~kJ} / \mathrm{mol}$, $x\left(\mathrm{OsO}_{4}\right)=2.25 \AA$ was deduced. Then, taking this distance as a benchmark and assuming that the molecule-surface distance is directly related to the size of the adsorbed molecules, $\Delta H_{\text {ads }}=-40.4 \mathrm{~kJ} / \mathrm{mol}$ for $\mathrm{RuO}_{4}$ and $\Delta H_{\text {ads }}=-36.3 \mathrm{~kJ} / \mathrm{mol}$ for $\mathrm{HsO}_{4}$ were obtained.

Several other types of interaction of the molecules with the surface, like interaction with adsorbed oxygen on the surface, were also considered. In summary, $\Delta H_{\text {ads }}=-40.4 \pm 1.5 \mathrm{~kJ} / \mathrm{mol}$ and $-36.7 \pm 1.5 \mathrm{~kJ} / \mathrm{mol}$, on the average, have been predicted for $\mathrm{RuO}_{4}$ and $\mathrm{HsO}_{4}$, respectively. Thus, $\mathrm{HsO}_{4}$ was expected to be almost equally or slightly more volatile than $\mathrm{OsO}_{4}$, with the difference in the adsorption enthalpy being of the order of the experimental uncertainty. This conclusion would also be in agreement with the higher covalence of $\mathrm{HsO}_{4}$ as compared to those of the lighter homologs.

3.2. Hydrolysis and Complex Formation of Group $\&-6$ Elements. In $\mathrm{HF}$ and $\mathrm{HCl}$ solutions, group 4-6 elements form mostly anionic complexes in various degree of hydrolysis. Differences in hydrolysis of compounds of elements belonging to the same chemical group are reflected by differences in their $K_{d}$ (distribution coefficient) values, since more hydrolysed complexes are worse extracted than less hydrolysed ones. In the following section, a model is described which defines stability of complexes being in equibrium with their hydrolysis products. Using this model, trends in $K_{d}$ were predicted for group 4, 5, and 6 elements for ion exchange separations from aqueous acidic solutions.

3.2.1. The Model. Reactions of complex formation in equilibrium with hydrolysis are expressed in a general form by the following equlibrium

$$
\begin{aligned}
x \mathrm{M}\left(\mathrm{H}_{2} \mathrm{O}\right)_{w^{\circ}}^{z+}+y \mathrm{OH}^{-}+a \mathrm{~L}^{-} \Leftrightarrow & \mathrm{M}_{x} \mathrm{O}_{u}(\mathrm{OH})_{y-2 u}\left(\mathrm{H}_{2} \mathrm{O}\right)_{w} \mathrm{~L}_{a}^{(x z-y-a)+} \\
& +\left(x w^{\circ}+u-w\right) \mathrm{H}_{2} \mathrm{O} .
\end{aligned}
$$

To calculate free energy of such a reaction in an efficient way, the following procedure was proposed. ${ }^{24}$ The free energy of a compound was supposed to be decomposed into the following parts $^{25}$

$$
\begin{aligned}
-\Delta G^{f}(u, v, w) / 2.3 R T= & \sum a_{i}+\sum a_{i j}-\log \left(u ! v ! w ! 2^{w}\right) \\
& +(2 u+v+1) \log 55.5
\end{aligned}
$$

and for a reaction

$$
\log K=-\Delta G^{r} / 2.3 R T,
$$


TABLE 3: Coulomb parts of the Gibbs free energies $\left(E^{\mathrm{c}}\right)$ and their changes $\left(\Delta E^{\mathrm{C}}\right)$ for the reaction $\mathrm{M}\left(\mathrm{H}_{2} \mathrm{O}\right)_{8}^{4+} \Leftrightarrow \mathrm{MF}_{6}^{2-}$ and $\mathrm{M}\left(\mathrm{H}_{2} \mathrm{O}\right)_{8}^{4+}$ $\Leftrightarrow \mathrm{MC}_{6}^{2-}$, where $\mathrm{M}=\mathrm{Zr}$, Hf, and Rf. ${ }^{29}$

\begin{tabular}{ccccc}
\hline $\begin{array}{c}\text { Energy } \\
/ \mathrm{eV}\end{array}$ & Compound & $\mathrm{Zr}$ & $\mathrm{Hf}$ & $\mathrm{Rf}$ \\
\hline$E^{C}$ & $\mathrm{M}\left(\mathrm{H}_{2} \mathrm{O}\right)_{8}^{4+}$ & -53.34 & -52.07 & -50.92 \\
$E^{C}$ & $\mathrm{MF}_{6}^{2-}$ & -2.60 & -1.18 & 0.23 \\
$E^{C}$ & $\mathrm{MCl}_{6}^{2-}$ & -1.21 & 0.41 & 2.13 \\
$\Delta E^{C}$ & $\left.\mathrm{M}_{\left(\mathrm{H}_{2} \mathrm{O}\right.}\right)_{8}^{4+} \Leftrightarrow \mathrm{MF}_{6}^{2-}$ & 50.75 & 50.88 & 51.15 \\
$\Delta E^{C}$ & $\mathrm{M}\left(\mathrm{H}_{2} \mathrm{O}\right)_{8}^{4+} \Leftrightarrow \mathrm{MCl}_{6}^{2-}$ & 52.15 & 52.50 & 53.06 \\
\hline
\end{tabular}

where $\Delta G^{r}$ is the difference in $\Delta G^{f}$ between products and starters of the reaction. The first term on the right-hand side of eq 6 , $\sum a_{i}$, is the non-electrostatic contribution from all the constituent atoms, $\sum a_{i}=k$ OP. The next term, $\sum a_{i j}$, is a sum of each pairwise electrostatic (Coulomb) interaction:

$$
E^{C}=\sum a_{i j}=-B \sum_{i j} Q_{i} Q_{j} / d_{i j}
$$

where $d_{i j}$ is the distance between moieties $i$ and $j ; Q_{i}$ and $Q_{j}$ are their effective charges and $B=2.3 R T e^{2} / \varepsilon$ is an independent constant. The last two terms in eq 6 are statistical: one is a correction for indistinguishable configurations of the species, and the other is a conversion to the molar scale of concentration for the entropy.

It was further suggested ${ }^{24}$ to calculate $\sum a_{i j}$ and $\sum a_{i}$ for each compound via the electronic density distribution data (the Mulliken numbers) obtained as a result of the fully relativistic DFT calculations of the electronic structure of the complexes of interest. The differences in those values for the left and the right parts of an equilibrium reaction plus the differences in the other terms of eq 6 define $\log K$. For that purpose, calculations of the electronic structure of numerous complexes of group 4-6 elements have been performed and free energies of the complex formation or hydrolysis reactions were defined. ${ }^{24,26-28}$ The results will be shown in the following subsections.

In all cases, the results have shown the hydrolysis/protonation or complex formation processes to be governed by changes in the electrostatic interaction, $\Delta E^{C}$, so that prediction of an equilibrium can be made with sufficient accuracy just by calculating electrostatic terms only. This electrostatic interaction should, however, be defined using calculated relativistic electronic density distribution data and not formal charges. Thus, knowing only $\Delta E^{C}, \log K$ could be defined for any reaction, as it is shown in the following sections for group 4, 5 , and 6 complexes.

3.2.2. Complex Formation of Group 4 Elements in $H F$ and $\mathrm{HCl}$ Solutions. In mixed solutions at $\mathrm{HF}$ between $10^{-3} \mathrm{M}$ and $10^{-2} \mathrm{M}$ and $0.1 \mathrm{M} \mathrm{HNO}_{3}$, i.e. at $\mathrm{pH} \cong 1$, the complex formation for group 4 elements can be described by the following equilibrium

$$
\mathrm{M}\left(\mathrm{H}_{2} \mathrm{O}\right)_{8}^{4+}+6 \mathrm{HL} \Leftrightarrow \mathrm{ML}_{6}^{2-}+8 \mathrm{H}_{2} \mathrm{O}+6 \mathrm{H}^{+}
$$

where $\mathrm{M}=\mathrm{Zr}$, $\mathrm{Hf}$, and $\mathrm{Rf}$, and $\mathrm{L}=\mathrm{F}$ or $\mathrm{Cl}$. To predict $\log K$ of reaction 9 , the DFT calculations of the electronic structure were performed for the $\mathrm{M}\left(\mathrm{H}_{2} \mathrm{O}\right)_{8}^{4+}, \mathrm{MF}_{6}^{2-}$, and $\mathrm{MCl}_{6}^{2-}$ complexes, where $\mathrm{M}=\mathrm{Zr}$, Hf, and $\mathrm{Rf}^{29}$ Geometry and bond lengths $\left(R_{e}\right)$ of $\mathrm{M}\left(\mathrm{H}_{2} \mathrm{O}\right)_{8}^{4+}\left(D_{2 d}\right.$-symmetry) and $\mathrm{MF}_{6}^{2-}$ were selected on the basis of analysis of the structural data for $\mathrm{Zr}$ and $\mathrm{Hf}$ and from calculated $R_{e}$ for some simpler Rf gas-phase compounds. ${ }^{30}$

The calculated electronic structure data show that the Rf complexes are very similar to those of $\mathrm{Zr}$ and $\mathrm{Hf}: \Delta E^{C}$ for reaction 9 (Table 3) indicate that $\mathrm{Rf}$ should form complexes in a similar way as $\mathrm{Zr}$ and $\mathrm{Hf}$, only at slightly higher HF concentrations. The sequence in the complex formation was, therefore, predicted as $\mathrm{Zr}>\mathrm{Hf}>\mathrm{Rf}$, with the differences in the $K_{d}$ values between the three elements being very small.

The theoretically obtained sequence for $\mathrm{Zr}$, Hf, and $\mathrm{Rf}$ proved to be in agreement with the experimental sequence for descending $K_{d}$ values in the sorption by CIX and for ascending $K_{d}$ values for $\mathrm{Zr}$ and $\mathrm{Hf}$ in the sorption by $\mathrm{AIX}^{3}$ The low sorption of
TABLE 4: Energies of $E^{\mathrm{C}}$ and $\Delta E^{\mathrm{C}}$ for the hydrolysis reaction $\mathrm{M}\left(\mathrm{H}_{2} \mathrm{O}\right)_{6}^{5+} \Leftrightarrow \mathrm{M}(\mathrm{OH})_{6}^{-}$, where $\mathrm{M}=\mathrm{Nb}, \mathrm{Ta}, \mathrm{Db}$, and $\mathrm{Pa} .{ }^{24}$

\begin{tabular}{llcccc}
\hline $\begin{array}{c}\text { Energy } \\
/ \mathrm{eV}\end{array}$ & Compound & $\mathrm{Nb}$ & $\mathrm{Ta}$ & $\mathrm{Db}$ & $\mathrm{Pa}$ \\
\hline$E^{C}$ & $\mathrm{M}(\mathrm{OH})_{6}^{-}$ & -21.74 & -23.33 & -21.48 & -19.53 \\
& $\mathrm{M}\left(\mathrm{H}_{2} \mathrm{O}\right)_{6}^{5+}$ & -21.92 & -25.38 & -25.37 & -29.71 \\
$\Delta E^{C}$ & & 0.18 & 2.05 & 3.89 & 9.18 \\
\hline
\end{tabular}

$\mathrm{Rf}$ at the AIX found in the experiments ${ }^{3}$ could be explained by a stronger competition of the counter ion $\mathrm{NO}_{3}^{-}$for the binding sites of the resin.

In $\mathrm{HCl}$ solutions, at the $\mathrm{HCl}$ concentrations above $6 \mathrm{M}$, complex formation should follow the same pattern as that for the HF solutions (no hydrolysis takes place). Results of the theoretical treatment of equilibrium 9 with the formation of the chlorocomplexes are summarized in Table 3 . The calculated $\Delta E^{C}$ indicate the same sequence in the complex formation, $\mathrm{Zr}>\mathrm{Hf}>\mathrm{Rf}$, for $\mathrm{HCl}$ solutions, as that for $\mathrm{HF}$ solutions.

3.2.3. Hydrolysis and Complex Formation of Group 5 Elements. As a cation, $\mathrm{Nb}$ is known to be stronger hydrolyzed as $\mathrm{Ta}$, though for the compounds of $\mathrm{Nb}$ and $\mathrm{Ta}$ the opposite trend is observed. ${ }^{25}$ The hydrolysis reaction (also for $\mathrm{Pa}$ ) proceeds very fast with the formation of the utmost hydrolysis product $\mathrm{M}(\mathrm{OH})_{6}^{-}$:

$$
\mathrm{M}\left(\mathrm{H}_{2} \mathrm{O}\right)_{6}^{5+} \Leftrightarrow \mathrm{M}(\mathrm{OH})_{6}^{-}+6 \mathrm{H}^{+}(\mathrm{M}=\mathrm{Nb}, \mathrm{Ta} \text {, and } \mathrm{Pa}) \text {. }
$$

To study hydrolysis of $\mathrm{Db}$ in comparison with that of the lighter homologs in the group, the free energy changes of reaction 10 were determined for $\mathrm{Nb}, \mathrm{Ta}, \mathrm{Db}$, and $\mathrm{Pa}$ on the basis of the calculations of the electronic structure of the indicated complexes using the DFT method. ${ }^{26}$ Geometry and bond lengths for the $\mathrm{Nb}, \mathrm{Ta}$, and $\mathrm{Pa}$ complexes were taken from experimental values on the basis of analysis of the numerous structural data. The bond lengths for the $\mathrm{Db}$ complexes were estimated from the calculated ionic radii. ${ }^{31}$

The results of the calculations are shown in Table 4. One can see that $E^{C}$ for $\mathrm{M}(\mathrm{OH})_{6}^{-}$and $\mathrm{M}\left(\mathrm{H}_{2} \mathrm{O}\right)_{6}^{5+}$, where $\mathrm{M}=\mathrm{Nb}$, Ta, and $\mathrm{Db}$, are rather similar, while those of $\mathrm{Pa}$ are different: $E^{C}$ (absolute value) of $\mathrm{Pa}(\mathrm{OH})_{6}^{-}$is lower than those of $\mathrm{Nb}, \mathrm{Ta}$, and $\mathrm{Db}$, while $E^{C}$ of $\mathrm{Pa}\left(\mathrm{H}_{2} \mathrm{O}\right)_{6}^{5+}$ is much higher. Obviously, $\mathrm{Pa}$ holds water molecules stronger than $\mathrm{Nb}, \mathrm{Ta}$, and $\mathrm{Db}$. The differences, $\Delta E^{C}$, also show strong resistance of $\mathrm{Pa}$ against hydrolysis, so that the trend for hydrolysis of group 5 elements is:

$$
\mathrm{Nb}>\mathrm{Ta}>\mathrm{Db} \gg \mathrm{Pa} .
$$

Thus, in agreement with experiment ${ }^{25} \mathrm{Nb}$ is confirmed to be more hydrolyzed than $\mathrm{Ta}$, and both of them to be much more hydrolysed than $\mathrm{Pa}$. $\mathrm{Db}$ is less hydrolyzed than $\mathrm{Nb}$ and $\mathrm{Ta}$, but much more than $\mathrm{Pa}$.

The formation of fluoride, chloride, and bromide complexes of group 5 elements undergoes the following complexation reaction

$$
\mathrm{M}(\mathrm{OH})_{6}^{-}+n \mathrm{HL} \Leftrightarrow \mathrm{MO}_{\mathrm{n}} \mathrm{L}_{6-n}^{-}+6 \mathrm{H}_{2} \mathrm{O}
$$

where $\mathrm{L}=\mathrm{F}, \mathrm{Cl}$, and $\mathrm{Br}$. As in the previous cases, calculations of the electronic structures of all various complexes of the group 5 elements have been performed using the DFT method and $\Delta E^{C}$ were defined on their basis (Table 5). ${ }^{26,27}$ The $\Delta E^{C}$ data show the following trend for formation of all the types of complexes:

$$
\Delta E^{C}: \quad \mathrm{Pa} \gg \mathrm{Nb}>\mathrm{Db}>\mathrm{Ta} .
$$

Thus, the theoretically obtained data show that, for all the types of complexes, those of $\mathrm{Pa}$ are formed in more dilute $\mathrm{HCl}$ solutions (starting with $\mathrm{Pa}(\mathrm{OH})_{2} \mathrm{Cl}_{4}^{-}$at $2-4 \mathrm{M}$ ), than those of $\mathrm{Nb}$. The complexes of $\mathrm{Nb}$ start to form next, while those of $\mathrm{Ta}$ are formed at the highest $\mathrm{HCl}$ molarities. Db was shown to form 
TABLE 5: $\Delta E^{\mathrm{C}}$ (in $\mathrm{eV}$ ) for reaction $\mathrm{M}(\mathrm{OH})_{6}^{-} \Leftrightarrow \mathrm{M}(\mathrm{OH})_{\mathrm{n}} \mathrm{Cl}_{\mathrm{m}}^{-}$, where $\mathrm{M}=\mathrm{Nb}, \mathrm{Ta}, \mathbf{D b}$, and $\mathrm{Pa}^{26}$

\begin{tabular}{cccc}
\hline Metal & $\mathrm{M}(\mathrm{OH})_{2} \mathrm{Cl}_{4}^{-}$ & $\mathrm{MOCl}_{4}^{-}$ & $\mathrm{MCl}_{6}^{-}$ \\
\hline $\mathrm{Nb}$ & 13.56 & 18.40 & 19.57 \\
$\mathrm{Ta}$ & 14.32 & 19.80 & 20.78 \\
$\mathrm{Db}$ & 14.29 & 19.67 & 20.46 \\
$\mathrm{~Pa}$ & 11.68 & 16.29 & 17.67 \\
\hline
\end{tabular}

TABLE 6: $\Delta E^{\mathrm{C}}$ (in $\mathrm{eV}$ ) for reaction $\mathrm{M}(\mathrm{OH})_{6}^{-} \Leftrightarrow \mathrm{ML}_{6}^{-}$, where $\mathrm{M}=$ $\mathrm{Nb}, \mathrm{Ta}, \mathrm{Db}$, and $\mathrm{Pa}$, and $\mathrm{L}=\mathrm{F}, \mathrm{Cl}$, and $\mathrm{Br}^{26,27}$

\begin{tabular}{cccc}
\hline Complex & $\mathrm{F}$ & $\mathrm{Cl}$ & $\mathrm{Br}$ \\
\hline $\mathrm{NbL}_{6}^{-}$ & 12.20 & 19.57 & 21.40 \\
$\mathrm{TaL}_{6}^{-}$ & 12.69 & 20.78 & 22.63 \\
$\mathrm{DbL}_{6}^{-}$ & 12.38 & 20.46 & 22.11 \\
$\mathrm{PaL}_{6}^{-}$ & 12.19 & 17.67 & 19.91 \\
\hline
\end{tabular}

complexes between those of $\mathrm{Nb}$ and $\mathrm{Ta}$. This theoretical conclusion (sequence 13) for $\mathrm{Nb}$ and $\mathrm{Ta}$ (sequence 12) is in agreement with the electrodialysis experiments. ${ }^{32}$

Comparison of the $\Delta E^{C}$ values for $\mathrm{M}(\mathrm{OH})_{2} \mathrm{Cl}_{4}^{-}, \mathrm{MOCl}_{4}^{-}$, and $\mathrm{MCl}_{6}^{-}$(Table 5) shows that in agreement with the experiment, the $\mathrm{M}(\mathrm{OH})_{2} \mathrm{Cl}_{4}^{-}$species are formed at lower $\mathrm{HCl}$ concentration, while $\mathrm{MCl}_{6}^{-}$at the highest concentrations, so that with increasing $\mathrm{HCl}$ concentration the complex formation changes in the order

$$
\mathrm{M}(\mathrm{OH})_{2} \mathrm{Cl}_{4}^{-}>\mathrm{MOCl}_{4}^{-}>\mathrm{MCl}_{6}^{-} \text {. }
$$

The theoretical analysis ${ }^{26}$ of the extraction mechanism of $\mathrm{Nb}$, $\mathrm{Ta}$, and $\mathrm{Pa}$ from aqueous $\mathrm{HCl}$ solution by anion exchange has shown that the extraction sequence is determined by the complex formation and partition of complexes between organic and aqueous phases. Taking this into account, an extraction position of $\mathrm{Db}$ from aqueous solutions above $4 \mathrm{M} \mathrm{HCl}$ was predicted $\mathrm{as}^{26}$

$$
\mathrm{Pa} \gg \mathrm{Nb} \geq \mathrm{Db}>\mathrm{Ta} .
$$

The theoretically predicted trend 15 was confirmed by the experiment on the extraction of $\mathrm{Db}$ and other group 5 homologs from $\mathrm{HCl}$ solutions. ${ }^{9}$ Thus, trends in the complex formation and extraction known for $\mathrm{Nb}, \mathrm{Ta}$, and $\mathrm{Pa}$ turned out to be inversed in going to $\mathrm{Db}$. This could not be predicted by any extrapolation of properties within the group, but came out as a result of considering real chemical equilibria and calculating relativistically the electronic structure of the complexes.

The calculations have also well reproduced the sequence in the formation of $\mathrm{ML}_{6}^{-}(\mathrm{M}=\mathrm{Nb}, \mathrm{Ta}, \mathrm{Db}$, and $\mathrm{Pa} ; \mathrm{L}=\mathrm{F}, \mathrm{Cl}$, and $\mathrm{Br}$ ) as a function of the ligand $\mathrm{L}, \mathrm{MF}_{6}^{-} \gg \mathrm{MCl}_{6}^{-}>\mathrm{MBr}_{6}^{-}$, as the data of Table 6 show.

3.2.4. Hydrolysis of Group 6 Elements. In $\mathrm{HNO}_{3}$ solutions, group 6 elements form oxocomplexes with a various degree of hydrolysis. Mo is known to be more hydrolyzed than W. ${ }^{25}$ The question about hydrolysis of $\mathrm{Sg}$ was open.

To study hydrolysis of group 6 elements, the following protonation equilibria (well-established for $\mathrm{Mo}^{33}$ ) have been consid$\operatorname{ered}^{28}$

$$
\begin{gathered}
\mathrm{MO}_{4}^{2-} \Leftrightarrow \mathrm{MO}_{3}(\mathrm{OH})^{-} \Leftrightarrow \mathrm{MO}_{2}(\mathrm{OH})_{2}\left(\mathrm{H}_{2} \mathrm{O}\right)_{2} \Leftrightarrow \\
\mathrm{MO}(\mathrm{OH})_{3}\left(\mathrm{H}_{2} \mathrm{O}\right)_{2}^{+} \Leftrightarrow \mathrm{M}(\mathrm{OH})_{4}\left(\mathrm{H}_{2} \mathrm{O}\right)_{2}^{2+} \Leftrightarrow \ldots \Leftrightarrow \mathrm{M}\left(\mathrm{H}_{2} \mathrm{O}\right)_{6}^{6+}
\end{gathered}
$$

where $\mathrm{M}=\mathrm{Mo}, \mathrm{W}$, and $\mathrm{Sg}$. For that purpose, the electronic structure calculations of all the molecular species indicated in the equilibria 16 were performed ${ }^{28}$ using the DFT method. Geometry and bond lengths of the Mo and $\mathrm{W}$ complexes were taken from experimental values by analyzing numerous structural data. ${ }^{34-36}$ The bond lengths for the $\mathrm{Sg}$ complexes were estimated on the basis of $R_{e}$ for some simpler $\mathrm{Sg}$ gas-phase compounds. ${ }^{37}$ The calculations were, as previously, restricted to the calculations of the ionic (Coulomb) and covalent parts of the molecular-ligand interaction energy using Mulliken numbers.
TABLE 7: Coulomb parts of the free energy changes $\left(\Delta E^{\mathrm{C}}\right)$ for the step-wise protonation of $\mathrm{MO}_{4}^{2-}$, where $\mathrm{M}=\mathrm{Mo}, \mathrm{W}$, and $\mathrm{Sg}^{28}$

\begin{tabular}{cccc}
\hline Reaction & \multicolumn{3}{c}{$\Delta E^{\mathrm{C}} / \mathrm{eV}$} \\
\cline { 2 - 4 } & $\mathrm{Mo}$ & $\mathrm{W}$ & $\mathrm{Sg}$ \\
\hline $\mathrm{MO}_{4}^{2-}+\mathrm{H}^{+} \Leftrightarrow \mathrm{MO}_{3}(\mathrm{OH})^{-}$ & -12.98 & -13.13 & -12.95 \\
$\mathrm{MO}_{3}(\mathrm{OH})^{-}+\mathrm{H}^{+}+2 \mathrm{H}_{2} \mathrm{O}$ & & & \\
$\Leftrightarrow \mathrm{MO}_{2}(\mathrm{OH})_{2}\left(\mathrm{H}_{2} \mathrm{O}\right)_{2}$ & -21.43 & -22.08 & -21.61 \\
$\mathrm{MO}_{2}(\mathrm{OH})_{2}\left(\mathrm{H}_{2} \mathrm{O}\right)_{2}+\mathrm{H}^{+}$ & & & \\
$\Leftrightarrow \mathrm{MO}(\mathrm{OH})_{3}\left(\mathrm{H}_{2} \mathrm{O}\right)_{2}^{+}$ & -5.84 & -6.35 & -6.65 \\
$\mathrm{MO}(\mathrm{OH})_{3}\left(\mathrm{H}_{2} \mathrm{O}\right)_{2}^{+}+\mathrm{H}^{+}$ & & & \\
$\Leftrightarrow \mathrm{M}(\mathrm{OH})_{4}\left(\mathrm{H}_{2} \mathrm{O}\right)_{2}^{2+}$ & -0.43 & -0.76 & -1.23 \\
$\mathrm{M}(\mathrm{OH})_{4}\left(\mathrm{H}_{2} \mathrm{O}\right)_{2}^{2+}+4 \mathrm{H}^{+}$ & & & \\
$\Leftrightarrow \ldots \mathrm{M}\left(\mathrm{H}_{2} \mathrm{O}\right)_{6}^{6+}$ & 41.97 & 38.71 & 37.11 \\
\hline$\Leftrightarrow$
\end{tabular}

Results of the calculations of $\Delta E^{C}$ for the step-wise protonation process 16 are given in Table 7. Comparing the $\Delta E^{C}$ data of Table 7 for negative complexes of $\mathrm{Mo}, \mathrm{W}$, and $\mathrm{Sg}$ one can see an extremum on $\mathrm{W}$ for the first two protonation steps: the largest negative values of $\Delta E^{C}$ for $\mathrm{W}$ mean its strongest preference for protonation, or the weakest preference for hydrolysis, which is in agreement with the experiments for Mo and $W .^{25}$ Thus, for the first two protonation steps involving the negative complexes of the elements, which are more covalent in comparison with the neutral and positively charged ones, the trend is reversed: $\mathrm{W}>\mathrm{Sg}>\mathrm{Mo}$. For the further protonation processes with the formation of the positively charged complexes, $\Delta E^{C}$ becomes smoothly more negative from $\mathrm{Mo}$ to $\mathrm{W}$ and to $\mathrm{Sg}$, so that the trend in the protonation is $\mathrm{Sg}>\mathrm{W}>\mathrm{Mo}$.

Hydrolysis constants for $\mathrm{Sg}$ were then defined using the established relation between $\Delta E^{C}$ and $\log K$

$$
\begin{aligned}
& \text { Mo: } \log K_{1} / \Delta E_{1}^{C}=3.7 / 12.98=0.29, \\
& \text { W }: \log K_{1} / \Delta E_{1}^{C}=3.8 / 13.13=0.29, \\
& \text { Mo }:\left[\log K_{1}+\log K_{2}\right] /\left[\Delta E_{1}^{C}+\Delta E_{2}^{C}\right]=7.50 / 34.01=0.22, \\
& \text { W }:\left[\log K_{1}+\log K_{2}\right] /\left[\Delta E_{1}^{C}+\Delta E_{2}^{C}\right]=8.1 / 35.21=0.23(17)
\end{aligned}
$$

(The $\log K$ values are from Reference 33). Thus, by using the fact that $\log K / \Delta E^{C}=$ const (eqs 17) and knowing $\Delta E^{C}$ for the $\mathrm{Sg}$ reactions $\log K_{1}(\mathrm{Sg})=3.73$ and $\log K_{1}+\log K_{2}(\mathrm{Sg})=7.5$ were defined. Other $\log K$ are given in Reference 28 .

Thus, the calculated $\Delta E^{C}$ s indicate that for the first two protonation steps involving more covalent compounds the increasing trend from Mo to $\mathrm{W}$ is not continued with $\mathrm{Sg}$ : $\mathrm{W}>\mathrm{Sg}>\mathrm{Mo}$. A similar reversed trend was observed in group 5 for the formation of chloro-, bromo-, and fluoro-complexes: $\mathrm{Nb}>\mathrm{Db}>\mathrm{Ta}^{9}{ }^{9,24}$ For the further protonation processes with the formation of the positively charged complexes, $\Delta E^{C}$ becomes smoothly more negative from Mo to $\mathrm{W}$, and to $\mathrm{Sg}$, so that the trend in the protonation process is: $\mathrm{Sg}>\mathrm{W}>\mathrm{Mo}$. These theoretically obtained sequences are in agreement with the experimental data on hydrolysis of $\mathrm{Mo}$ and $\mathrm{W}^{25}$ and, recently, on $\mathrm{Sg}^{10}$

\section{Conclusions}

The calculations of the electronic structures of various gasphase and aqueous-phase compounds of the transactinides and their homologs have shown that the former are full homologs of the lighter $4 d$ and $5 d$ elements and exhibit very similar properties. The predicted enthalpies of adsorption of $\mathrm{BhO}_{3} \mathrm{Cl}$ and $\mathrm{HsO}_{4}$ indicate that trends in volatility known for the lighter compounds should be continued with the transactinides.

The study of the hydrolysis and complex formation both theoretically and experimentally has indicated that some trends could be reversed in the groups, as it was in the case of the group 5 and 6 complex formation. A careful analysis of chemical equilibria and relativistic calculations proved, therefore, to be indispensable in predictions of the outcome of liquid chromatography separation experiments. 
Acknowledgements. The calculations were performed on the Linux station of the GSI, Darmstadt. The author thanks T. Bastug for help in the calculations. The DFT program developed in the group of Prof. B. Fricke, University of Kassel, was used for the calculations.

\section{References}

(1) R. Eichler, W. Brüchle, R. Dressler, Ch. E. Düllmann, B. Eichler, H. W. Gäggeler, K. E. Gregorich, D. C. Hoffman, S. Hübener, D. T. Jost, U. W. Kirbach, C. A. Laue, V. M. Lavanchy, H. Nitsche, J. B. Patin, D. Piguet, M. Schädel, D. A. Shaughnessy, D. A. Strellis, S. Taut, L. Tobler, Y. S. Tsyganov, A. Türler, A. Vahle, P. A. Wilk, and A. B. Yakushev, Nature 407, 63 (2000).

(2) Ch. E. Düllmann, A. Türler, D. T. Jost, D. Piguet, H. Blümer, B. Eichler, R. Eichler, and H. W. Gäggeler, $E x-$ tended Abstracts of the 5th International Conference on Nuclear and Radiochemistry, Pontresina, Sep. 3-8, 2000, Vol. 1, p. 199.

(3) E. Strub, J. V. Kratz, A. Kronenberg, A. Nähler, P. Thörle, S. Zauner, W. Brüchle, E. Jäger, M. Schädel, B. Schausten, E. Schimpf, Li Zongwei, U. Kirbach, D. Schumann, D. Jost, A. Türler, M. Asai, Y. Nagame, M. Sakama, K. Tsukada, H. W. Gäggeler, and J. P. Glatz, Radiochim. Acta 88, 265 (2000).

(4) H. Haba, The 5th Workshop on the Chemistry of the Heaviest Elements, Hasliberg, Aug. 26-29, 2001.

(5) J. V. Kratz, Heavy Elements and Related New Phenomena, edited by W. Greiner and R. K. Gupta (World Scientific, Singapore, 1999), p. 129.

(6) R. Günther, W. Paulus, J. V. Kratz, A. Seibert, P. Thörle, S. Zauner, W. Brüchle, E. Jäger, V. Pershina, M. Schädel, B. Schausten, D. Schumann, B. Eichler, H. W. Gäggeler, D. T. Jost, and A. Türler, Radiochim. Acta 80, 121 (1998).

(7) A. Bilewicz, S. Siekierski, C. D. Kacher, K. E. Gregorich, D. M. Lee, N. J. Stoyer, B. Kadkhodayan, S. A. Kreek, M. R. Lane, E. R. Sylwester, M. P. Neu, M. F. Mohar, and D. C. Hoffman, Radiochim. Acta 75, 121 (1996).

(8) K. R. Czerwinski, Ph.D. Thesis, University of California, Lawrence Berkeley National Laboratory Report LBL32233 (1992).

(9) W. Paulus, J. V. Kratz, E. Strub, S. Zauner, W. Brüchle, V. Pershina, M. Schädel, B. Schausten, J. L. Adams, K. E. Gregorich, D. C. Hoffman, M. R. Lane, C. Laue, D. M. Lee, C. A. McGrath, D. K. Shaughnessy, D. A. Strellis, and E. R. Sylwester, Radiochim. Acta 84, 69 (1999).
(10) M. Schädel, W. Brüchle, E. Jäger, B. Schausten, G. Wirth, W. Paulus, R. Günter, K. Eberhardt, J. V. Kratz, A. Seibert, E. Strub, P. Thörle, N. Trautmann, A. Waldek, S. Zauner, D. Schumann, U. Kirbach, B. Kubica, R. Misiak, Y. Nagame, and K. E. Gregorich, Radiochim. Acta 83, 163 (1998).

(11) V. Pershina, Chem. Rev. 96, 1977 (1996).

(12) V. Pershina and B. Fricke, Heavy Elements and Related New Phenomena, edited by W. Greiner and R. K. Gupta (World Scientific, Singapore, 1999), p. 194.

(13) T. Bastug, W.-D. Sepp, D. Kolb, B. Fricke, G. te Velde, and E. J. Baerends, J. Phys. B 28, 2325 (1995).

(14) S. Varga, B. Fricke, M. Hirata, T. Bastug, V. Pershina, and S. Fritzsche, J. Phys. Chem. 104, 6495 (2000).

(15) T. Bastug, Doctoral Thesis, University of Kassel, 1994.

(16) P. M. Boerrigter, G. te Velde, and E. J. Baerends, Int. J. Quant. Chem. 33, 87 (1988).

(17) A. D. Becke, Phys. Rev. A 38, 3098 (1988).

(18) J. P. Perdew, Phys. Rev. B 33, 8822 (1986).

(19) E. Engel, S. Keller, and R. M. Dreizler, Phys. Rev. A 53, 1367 (1996).

(20) R. S. Mulliken, J. Chem. Phys. 23, 1833 (1955).

(21) V. Pershina and T. Bastug, J. Chem. Phys. 113, 1441 (2000).

(22) V. Pershina, T. Bastug, B. Fricke, and S. Varga, J. Chem. Phys. 115, 792 (2001).

(23) P. Burroughs, S. Evans, A. Hamnett, A. F. Orchard, and N. V. Richardson, J. Chem. Soc. Faraday Trans. 2, 70, 1895 (1974).

(24) V. Pershina, Radiochim. Acta 80, 65 (1998).

(25) C. F. Baes, Jr. and R. E. Mesmer, The Hydrolysis of Cations (John Wiley, New York, 1976).

(26) V. Pershina, Radiochim. Acta 80, 75 (1998).

(27) V. Pershina and T. Bastug, Radiochim. Acta 84, 79 (1999).

(28) V. Pershina and J. V. Kratz, Inorg. Chem. 40, 776 (2001).

(29) V. Pershina, D. Trubert, C. Le Naour, and J. V. Kratz, Radiochim. Acta (in press).

(30) S. Varga, B. Fricke, M. Hirata, T. Bastug, V. Pershina, and S. Fritzsche, J. Phys. Chem. 104, 6495 (2000).

(31) B. Fricke, E. Johnson, and G. M. Rivera, Radiochim. Acta 62, 17 (1993).

(32) B. I. Nabivanetz, Russ. J. Inorg. Chem. 9, 590 (1964).

(33) K. H. Tytko, Polyhedron 5, 497 (1986).

(34) F. A. Schröder, Acta Crystallorg. B 31, 2294 (1975).

(35) W. P. Griffith, Coord. Chem. Rev. 5, 459 (1970).

(36) F. A. Cotton and R. M. Wing, Inorg. Chem. 4, 867 (1965).

(37) Y.-K. Han, S.-K. Son, Y. J. Choi, and Y. S. Lee, J. Phys. Chem. 103, 9109 (1999). 